\title{
A enxertia na produção de mudas de hortaliças
}

\author{
Grafting of vegetable crops
}

Roberta Marins Peil ${ }^{1}$

- REVISÃO BIBLIOGRÁFICA -

\section{RESUMO}

\begin{abstract}
A enxertia, na olericultura, é uma técnica empregada para plantas das Famílias Solanaceae e Cucurbitaceae e objetiva conferir resistência às mudas. Desta forma, possibilita o cultivo em áreas contaminadas por patógenos de solo ou confere habilidades em relação a determinadas condições edafoclimáticas (resistência à baixa temperatura, à seca, ao excesso de umidade e aumento da capacidade de absorção de nutrientes). o presente trabalho apresenta o estado atual do conhecimento sobre a enxertia de hortaliças, enfocando aspectos relacionados à compatibilidade entre plantas e à cicatrização do enxerto. Dáse especial atenção à descrição dos métodos de enxertia e a sua adequação às diferentes espécies de hortaliças.
\end{abstract}

Palavras-chave: muda, plântula, enxerto, porta-enxerto, solanáceas, cucurbitáceas.

\section{ABSTRACT}

The grafting of vegetable crops aims to introduce resistance for Solanaceous and Cucurbits plants. It is a way of overcoming soil-born diseases or introducing abilities related to a certain soil-climatic condition (cold or drought resistance, wet endurance and improvement of nutrients absorption ability). In this paper, the state of art of vegetable crops grafting is presented foccusing on aspects concerning to plants compatibility and percentage of grafting taking. Special attention is paid to the description of grafting methods and its suitability to the different species of vegetable crops.

Key words: transplant, seedling, scion, rootstock, Solanaceous, Cucurbits.

\section{INTRODUÇ̃̃O}

A enxertia na produção comercial de mudas de hortaliças é uma técnica de uso recente no Brasil.
Entretanto, em países como Japão, Holanda e Espanha, onde a produção de hortaliças apresenta um caráter mais intensivo, esta técnica vem sendo adotada comumente por uma parte significativa dos olericultores e produtores de mudas. A técnica de enxertia herbácea iniciou no Japão, no início do século passado, com o objetivo de prevenir a fusariose na cultura da melancia. Essa técnica espalhou-se de tal maneira naquele país que, na década de $90,95 \%, 60 \%$, $62 \%, 30 \%$ e $10 \%$ da área ocupada, respectivamente, com as culturas da melancia, do pepino, do melão, da berinjela e do tomateiro era plantada com mudas enxertadas (SHINOHARA, 1994). Na Europa, a enxertia de hortaliças é utilizada desde a década de 40 , sendo os agricultores holandeses os precursores desta técnica na cultura do tomate (GONZÁLES, 1999). No Brasil, alguns produtores paulistas de pepino japonês vêm adotando a enxertia como uma alternativa de produção, que objetiva diminuir as perdas ocasionadas por fungos de solo e nematóides e, também, melhorar a qualidade visual dos frutos (CANIZARES \& GOTO, 1999).

Deve-se considerar que nem todas as espécies apresentam características morfo-fisiológicas que possibilitam a enxertia. Assim sendo, entre as espécies de hortaliças, somente as das Famílias Solanaceae (tomate, pimentão e berinjela) e Cucurbitaceae (melancia, melão, pepino e abóbora) são comumente enxertadas.

No presente trabalho, o estado atual do conhecimento sobre a enxertia herbácea de hortaliças é discutido, enfocando-se os seus principais objetivos, as características adequadas de um porta-enxerto,

${ }^{1}$ Engenheiro Agrônomo, Doutor, Professor Adjunto, Departamento de Fitotecnia, Faculdade de Agronomia Eliseu Maciel, Universidade Federal de Pelotas, CP 354, 96.010-900, Pelotas, RS. Email: rmpeil@ufpel.tche.br 
alguns aspectos relacionados à compatibilidade entre plantas e à cicatrização do enxerto. Dar-se-á ênfase à descrição dos diferentes métodos de enxertia e a sua adequação às Famílias Solanaceae e Cucurbitaceae.

\section{OBJETIVOS DA ENXERTIA}

O principal objetivo que se pretende alcançar com a enxertia de hortaliças é obter resistência a doenças do solo (Tabela 1) e, portanto, possibilitar o cultivo de determinadas espécies em áreas contaminadas por patógenos. A enxertia, como método de controle de patógenos do solo, tem como fim evitar o contato da planta sensível com o agente patógeno. Enxerta-se a cultivar comercial sobre um porta-enxerto resistente, pertencente a outra cultivar, espécie ou gênero da mesma família botânica. O porta-enxerto resistente se mantém sadio, assumindo a função de absorver água e nutrientes do solo, ao mesmo tempo em que isola a cultivar sensível do patógeno. $\mathrm{Na}$ maioria dos casos, a planta resultante do processo de enxertia apresenta o sistema radicular do porta-enxerto e a parte aérea da cultivar. Portanto, esta é uma técnica alternativa a outros métodos de controle de doenças (cultivar, desinfecção do solo, uso de fungicidas, etc.) e que não contamina o meio ambiente. No caso da cultura do tomate, a enxertia também pode ser utilizada para proporcionar resistência ao vírus do mosaico do tabaco (TMV) (TAKII SEED, s/d).

Além de proporcionar resistência a doenças, esta técnica pode ser empregada com outros fins (Tabela 2), como a introdução de resistência às baixas temperaturas do solo no cultivo de inverno do pepino (PEIL et al., 1998) e no cultivo forçado da melancia, de resistência à seca na cultura da abóbora moranga e de resistência ao excesso de umidade e para aumentar a capacidade de absorção de nutrientes na cultura da melancia (NAWASHIRO, 1994).

\section{PROPRIEDADES DE UM PORTA-ENXERTO}

Em linhas gerais, um porta-enxerto deve reunir as seguintes características: imunidade à doença que se pretende controlar, quando este for o objetivo da enxertia; boa resistência aos demais patógenos do solo; vigor e rusticidade; boa afinidade com a cultivar enxertada; condições morfológicas ótimas para a realização da enxertia (tamanho do hipocótilo, consistência etc.); e não afetar desfavoravelmente a qualidade dos frutos.

Um porta-enxerto vigoroso faz com que a planta enxertada também seja vigorosa, o que permite diminuir a densidade de plantio, sem que haja prejuízos à produção. Em experimentos realizados por PEIL \& GÁLVEZ (1999), verificou-se que plantas de tomate enxertadas e conduzidas com duas hastes, transplantadas em baixa densidade, apresentaram igual rendimento por área que plantas não enxertadas conduzidas com uma única haste e cultivadas com o dobro da densidade. Desta forma, quando o fator mãode-obra não for limitante, o uso de plantas enxertadas pode diminuir o custo de implantação da cultura, além de possibilitar o plantio mais cedo, já que as raízes do porta-enxerto, normalmente, conseguem se desenvolver em condições de temperatura mais baixa do solo.

$\mathrm{Na}$ escolha do porta-enxerto devem ser observados outros aspectos, além do fator de resistência. Para exemplificar, podem-se citar o porongo e a abóbora, empregados como porta-enxertos na cultura da melancia. O primeiro apresenta como vantagens uma alta resistência ao fusario da melancia e à seca, embora seja suscetível à antracnose e ao

Tabela 1 - Porta-enxertos e doenças controladas com o uso da enxertia em hortaliças.

\begin{tabular}{|c|c|}
\hline Porta-enxerto & Doenças \\
\hline Tomate & $\begin{array}{l}\text { Podridão da raiz (Pyrenochaeta lycopersici), murcha de fusarium (Fusarium oxysporum f.sp. lycopersici), } \\
\text { murcha bacteriana (Pseudomonas solanacearum), murcha de verticillium (Verticillium albo-atrum), nematóides, } \\
\text { TMV }\end{array}$ \\
\hline Berinjela & $\begin{array}{l}\text { Murcha de verticillium (Verticillium albo-atrum), murcha de fusarium (Fusarium oxysporum f.sp. melongena), } \\
\text { murcha bacteriana (Pseudomonas solanacearum), nematóides }\end{array}$ \\
\hline $\begin{array}{l}\text { Abóbora moranga } \\
\text { (Cucurbita maxima) }\end{array}$ & $\begin{array}{l}\text { Murcha de fusarium do pepino (Fusarium oxysporum f.sp. cucumerinum), murcha de fusarium da melancia } \\
\text { (Fusarium oxysporum f.sp. niveum) }\end{array}$ \\
\hline $\begin{array}{l}\text { Porongo (Lagenaria } \\
\text { leucantha var. } \\
\text { gourda) }\end{array}$ & Murcha de fusarium da melancia (Fusarium oxysporum f.sp. niveum) \\
\hline Melão & Murcha de fusarium do melão (Fusarium oxysporum f.sp. melonis) \\
\hline
\end{tabular}

Fontes: NAWASHIRO (1994) e TAKII SEED (s/d).

Ciência Rural, v. 33, n. 6, nov-dez, 2003. 
Tabela 2 - Resistência comparativa (relativa a fatores ambientais adversos) entre as diferentes espécies de cucurbitáceas utilizadas como porta-enxertos.

\begin{tabular}{ll}
\hline Fator meio-ambiental & $\begin{array}{l}\text { Resistência comparativa entre } \\
\text { espécies }\end{array}$ \\
\hline $\begin{array}{l}\text { Baixa temperatura } \\
\text { Seca }\end{array}$ & $\begin{array}{l}\text { Abóbora }>\text { Porongo }>\text { Melancia } \\
\text { Melancia }>\text { Porongo }>\text { Abóbora }\end{array}$ \\
$\begin{array}{l}\text { Excesso de umidade do solo } \\
\text { Habilidade de absorção de } \\
\text { nutrientes }\end{array}$ & Abóbora $>$ Porongo $>$ Melancia \\
\hline
\end{tabular}

Fonte: NAWASHIRO (1994).

fusario do porongo. Já a abóbora apresenta resistência à umidade do solo, à maioria dos patógenos de solo e à antracnose, acarretando, porém a perda de sabor dos frutos.

\section{COMPATIBILIDADE ENTRE PLANTAS}

A compatibilidade é definida como a capacidade de duas plantas diferentes, unidas pela enxertia, conviverem satisfatoriamente, como uma única planta (GONZÁLEZ, 1999).

Para garantir o sucesso da enxertia, é necessário que haja coincidência entre os tecidos próximos ao câmbio, que gera o calo ou cicatriz. Não existe nenhum método capaz de predizer o resultado de uma enxertia, entretanto, em linhas gerais, se pode dizer que quanto maior a afinidade botânica entre as espécies, maior a probabilidade de sobrevivência do enxerto (Tabela 3).

A afinidade compreende aspectos morfológicos e fisiológicos das plantas. A afinidade morfológica, anatômica e de constituição dos tecidos se refere a que os vasos condutores das duas plantas que se unem tenham diâmetros semelhantes e

Tabela 3 - Compatibilidade de enxertia entre diferentes espécies de hortaliças.

\begin{tabular}{llllll}
\hline \multirow{5}{*}{$\begin{array}{l}\text { Porta- } \\
\text { enxerto }\end{array}$} & Tomate & Berinjela & Pepino & Melancia & Melão \\
\cline { 2 - 6 } & Tonxto & & - & - \\
\hline Tomate & Boa & - & - & - & - \\
Berinjela & - & Boa & - & - & Média \\
Abóboras & - & - & Boa & Boa & - \\
Porongo & - & - & - & Boa & - \\
Melancia & - & - & - & Boa & - \\
Melão & - & - & - & - & Boa \\
\hline
\end{tabular}

Fontes: NAWASHIRO (1994) e TAKII SEED (s/d). estejam, aproximadamente, em igual número. Já a afinidade fisiológica está relacionada à quantidade $\mathrm{e}$ composição da seiva.

A boa aptidão para a enxertia que apresentam as espécies pertencentes às Famílias Solanaceae e Cucurbitaceae parece estar relacionada à extensão do câmbio. Apesar de, comercialmente, serem enxertados sobre plantas da mesma espécie, o tomateiro e a berinjela são compatíveis com uma quantidade ampla de gêneros e espécies, enquanto o pimentão somente pode ser enxertado sobre plantas da mesma espécie. A tabela 4 mostra uma série de materiais genéticos indicados como porta-enxertos e que vêm sendo comercializados pelas empresas produtoras de sementes.

A diferença entre enxerto compatível e incompatível não está bem definida. Entre espécies que apresentam uma estreita relação e são enxertadas com facilidade, até outras que não estão relacionadas entre si e são incapazes de unirem-se, existe uma graduação intermediária de plantas que cicatrizam o ponto de enxertia, mas que, com o passar do tempo, apresentam sintomas de desordens no ponto de união ou crescimento anormal. Segundo GONZÁLEZ (1999), a incompatibilidade se manifesta, normalmente, com algum dos seguintes sintomas: baixo índice de sobrevivência do enxerto; amarelecimento das folhas, desfoliação e falta de crescimento; enrolamento das folhas e morte imediata da planta; diferenças marcantes na velocidade de crescimento entre porta-enxerto e cultivar; crescimento excessivo do ponto de enxertia, ou na zona próxima a este; e ruptura do ponto de enxertia.

\section{CICATRIZAÇÃO DO ENXERTO}

Segundo HARTMANN \& KESTER (1967), a cicatrização do ponto de enxertia ocorre da seguinte maneira: a) parte-se do princípio de que o tecido recém cortado da cultivar foi colocado em contato firme e íntimo com o tecido recém cortado do porta-enxerto, de modo que as regiões do câmbio de ambas as plantas se encontrem muito próximas. As condições de temperatura e umidade devem ser às adequadas para favorecer a atividade das camadas de células recém expostas e das circundantes a estas; b) as camadas exteriores expostas na região do câmbio, tanto da cultivar como do porta-enxerto, produzem células parenquimatosas, que logo se misturam e entrelaçam, formando o que normalmente se denomina de "calo"; c) no tecido caloso formado, algumas células, que se encontram alinhadas com o câmbio intacto da cultivar e do 
Tabela 4 - Porta enxertos comercias recomendados para diferentes espécies de hortaliças.

\begin{tabular}{|c|c|c|c|c|c|c|c|}
\hline \multirow{2}{*}{ Porta-enxerto } & \multicolumn{5}{|c|}{ Adequado para: } & \multirow{2}{*}{ Resistência } & \multirow{2}{*}{ Empresa } \\
\hline & Tomate & Berinjela & Pepino & Melancia & Melão & & \\
\hline \multicolumn{8}{|l|}{ Tomate } \\
\hline F1 Helper-M & $x$ & & & & & $\mathrm{~B}, \mathrm{~V}, \mathrm{~F} 1, \mathrm{~F} 2 \mathrm{~N}$ & Takii Seed \\
\hline F1 Achilles-M & $x$ & & & & & $\mathrm{~B}, \mathrm{~V}, \mathrm{~F} 1, \mathrm{~N}$ & Takii Seed \\
\hline F1 Tie-up $\mathrm{N}^{0} 1$ & $x$ & & & & & $\mathrm{~K}, \mathrm{~N}, \mathrm{~V}, \mathrm{~F} 1, \mathrm{TMV}$ & Takii Seed \\
\hline F1 Tie-up $N^{0} 2$ & $x$ & & & & & $\mathrm{~K}, \mathrm{~N}, \mathrm{~V}, \mathrm{~F} 1, \mathrm{~F} 2, \mathrm{TMV}$ & Takii Seed \\
\hline F1 Anchor-T & $x$ & & & & & $\mathrm{~B}, \mathrm{~V}, \mathrm{~F} 1, \mathrm{~F} 2, \mathrm{~N}, \mathrm{TMV}$ & Takii Seed \\
\hline F1 New $\mathrm{N}^{0} 1$ & $x$ & & & & & $\mathrm{~K}, \mathrm{~N}, \mathrm{~V}, \mathrm{~F} 1$ & Takii Seed \\
\hline F1 Healthy & $x$ & & & & & $\mathrm{~B}, \mathrm{~V}, \mathrm{~F} 1, \mathrm{~N}$ & Takii Seed \\
\hline F1 Kage & $x$ & & & & & $\mathrm{~B}, \mathrm{~N}, \mathrm{~V}, \mathrm{~F} 1, \mathrm{~F} 2, \mathrm{TMV}$ & Takii Seed \\
\hline Beuafort & $x$ & & & & & $\mathrm{~K}, \mathrm{~F}$ & De Ruiter \\
\hline Vigomax & $x$ & & & & & $\mathrm{~K}$ & De Ruiter \\
\hline \multicolumn{8}{|l|}{ Berinjela } \\
\hline F1 Meet & & $x$ & & & & $\mathrm{~V}, \mathrm{~F}$ & Takii Seed \\
\hline F1 Caravan & & $x$ & & & & $\mathrm{~V}, \mathrm{~F}$ & Takii Seed \\
\hline \multicolumn{8}{|c|}{$\begin{array}{l}\text { Abóbora (C. máxima } \times \text { x } C \text {. } \\
\text { moschata) }\end{array}$} \\
\hline F1Tetsukabuto & & & $x$ & $x$ & $x$ & $\mathrm{~F}$ & Takii Seed \\
\hline F1 Patron & & & $x$ & $x$ & & $\mathrm{~F}$ & Takii Seed \\
\hline F1 Just & & & $x$ & $x$ & $x$ & $\mathrm{~F}$ & Takii Seed \\
\hline RS841 & & & & $x$ & & & Royal Sluis \\
\hline Shintoza & & & & $x$ & & & Intersemila \\
\hline Brava & & & & $x$ & & & Petoseed \\
\hline Ferro & & & & $x$ & & & RijkZwaan \\
\hline Excite Ikki & & & $x$ & & & $\mathrm{~F}, \mathrm{~N}$ & \\
\hline \multicolumn{8}{|l|}{ Porongo } \\
\hline Friend & & & & $x$ & & $\mathrm{~F}$ & Takii Seed \\
\hline \multicolumn{8}{|l|}{ Melancia } \\
\hline F1 Toughness & & & & $x$ & & $\mathrm{~F}$ & Takii Seed \\
\hline \multicolumn{8}{|l|}{ Melão } \\
\hline F1 Base & & & & & $x$ & F & Takii Seed \\
\hline
\end{tabular}

Resistência: B: Pseudomonas solanacearum, V: Verticillium, F: Fusarium, N: nematoides, TMV: Vírus do mosaico do fumo, K: Pyrenochaeta lycopersici.

porta-enxerto, se diferenciam em novas células cambiais; d) as novas células cambiais produzem tecido vascular novo, xilema no interior e floema no exterior, o que é pré-requisito necessário para que a união das plantas tenha sucesso.

Entre os fatores que promovem a cicatrização do enxerto destacam-se a temperatura ambiente não demasiado alta e a umidade elevada no momento da enxertia. A presença de oxigênio no ponto de enxertia (o que favorece a produção do tecido caloso); uma ampla superfície de contato entre cultivar e porta-enxerto; cuidados fitossanitários para prevenir infecções por patógenos nas feridas produzidas ao enxertar; e condições ambientais pós-enxertia adequadas, para que tanto a cultivar como o portaenxerto não sofram estresse hídrico, são, também, fatores determinantes para o sucesso da enxertia.

\section{MÉTODOS DE ENXERTIA}

Existe uma grande variedade de métodos de enxertia de hortaliças. Entretanto, há dois métodos básicos que, com suas derivações, englobam todos os demais: enxertia por aproximação e por estaca. A eleição do método de enxertia deve considerar, além da espécie, as vantagens e desvantagens de cada um e relacionálas com a realidade do produtor de mudas. 
Uma questão importante a considerar para o sucesso da enxertia é que enxerto e porta-enxerto se encontrem nos estádios de crescimento adequados a cada método. Uma vez que as plantas utilizadas como enxerto e porta-enxerto podem apresentar velocidades de crescimento diferenciadas, é necessário programar as suas semeaduras, de maneira que ambas atinjam conjuntamente os respectivos estádios de crescimento adequados, os quais dependerão da espécie e do método de enxertia adotado (Figuras 1a e 1b).

\section{Enxertia por aproximação}

É um método adequado para as cucurbitáceas, não sendo empregado com o mesmo sucesso em solanáceas. Neste método, durante o processo de cicatrização do enxerto, os dois sistemas radiculares, do enxerto e do porta-enxerto, são mantidos.

A figura 1a mostra o esquema de semeadura para produção de plântulas a serem utilizadas no método de aproximação. A modo de exemplo: o pepino e a melancia apresentam intensidade de crescimento inferior à intensidade de crescimento da abóbora, utilizada como portaenxerto, havendo a necessidade de semeá-los de 5 (melancia) a 3 dias (pepino) antes desta. Se o porongo for o porta-enxerto selecionado, deve-se semeá-lo no mesmo dia que a melancia ou dois dias antes que o pepino, caso este último seja a espécie a ser enxertada. $O$ tempo médio entre a semeadura da cultivar e o transplante é de 30 a 40 dias neste método.

A operação de enxertia é difícil (Figura 2), entretanto, o manejo das plantas após a enxertia é facilitado. As plantas devem permanecer sombreadas até o dia seguinte à enxertia, sendo, a partir de então, mantidas sob condições normais de estufa. O índice de sobrevivência é superior ao observado com o método de enxertia por estaca (NAWASHIRO, 1994).

\section{Enxertia por estaca}

Neste método, une-se a porção apical do enxerto (estaca) à planta porta-enxerto, sendo eliminado o sistema radicular do primeiro no momento da enxertia. A operação de enxertia é mais fácil do que no método de aproximação, entretanto, o manejo deve ser mais cuidadoso no que se refere às condições ambientais pós-enxertia (Tabela 5), principalmente no que diz respeito às condições de luminosidade. Em alguns países, na produção comercial de mudas, as plantas são colocadas em câmaras de crescimento com ambiente completamente controlado durante o período de pós-enxertia (SHINOHARA, 1994; GONZÁLEZ, 1999). No Japão, à escala de agricultor, as condições ambientais requeridas neste período são parcialmente atendidas através do manejo de pequenos túneis plásticos construídos para tal fim no interior da estufa de produção de mudas (NAWASHIRO, 1994). Durante os dois dias seguintes ao final do período de pós-enxertia, deve-se realizar a aclimatação das plantas, colocando-as durante algumas poucas horas sob as condições normais da estufa. Normalmente, a partir do 9 dia após a enxertia, as plantas já podem ser expostas às condições ambientais normais da estufa de cultivo.

O método apresenta três derivações: enxertia por fenda, por perfuração apical e por estaca terminal. Devido à similaridade entre as duas

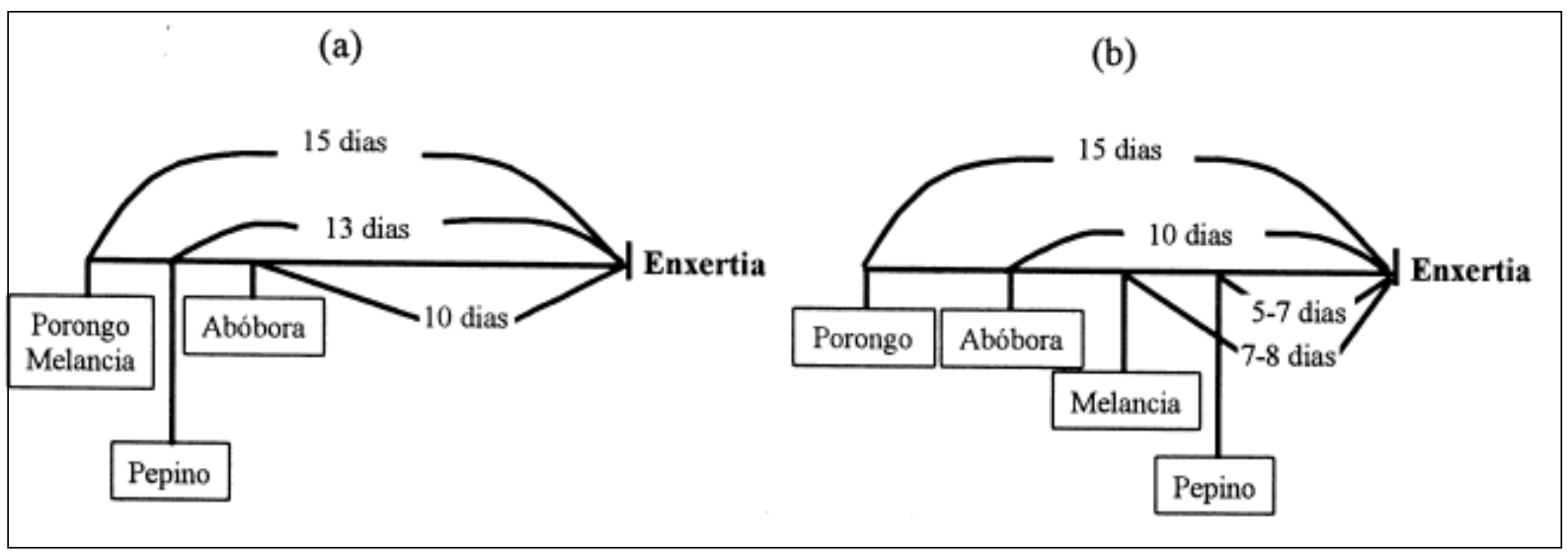

Figura 1 - Esquema para semeadura das espécies utilizadas como enxerto (melancia e pepino) e porta-enxerto (porongo e abóbora) no método de enxertia por aproximação (a) e nos métodos de enxertia por fenda e por perfuração apical (b).

Ciência Rural, v. 33, n. 6, nov-dez, 2003. 


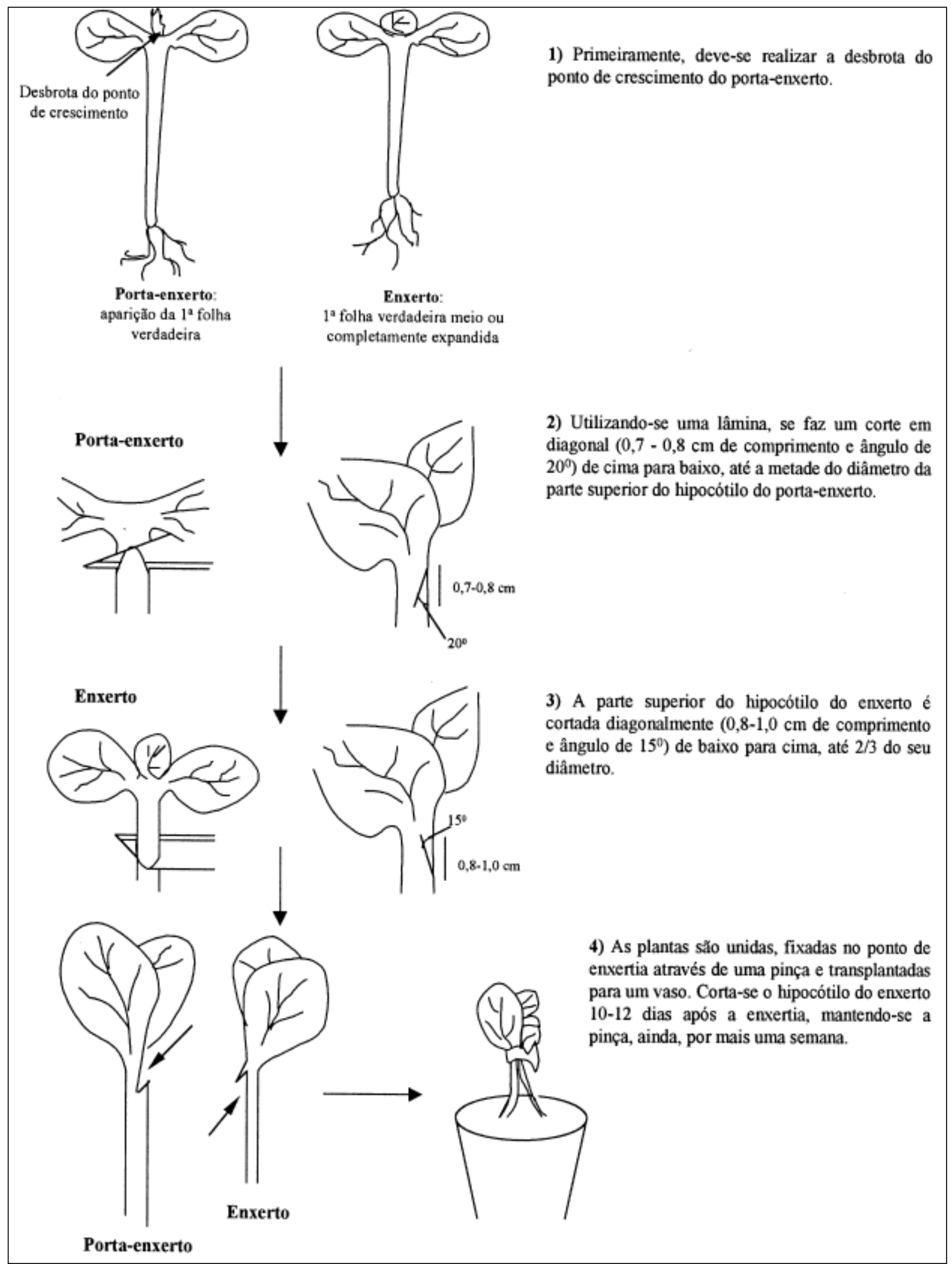

Figura 2 - Representação esquemática da operação de enxertia por aproximação de cucurbitáceas.

Ciência Rural, v. 33, n. 6, nov-dez, 2003. 
Tabela 5 - Condições ambientais ótimas no período pós-enxertia de hortaliças (aproximadamente 7-8 dias).

\begin{tabular}{ll}
\hline Fator meio-ambiental & Parâmetro \\
\hline Temperatura (dia/ noite) & $28 / 25^{\circ} \mathrm{C}$ \\
Umidade relativa & $90 \%$. \\
Luz & Ausência nos 2 primeiros dias e aumento progressivo diário, de modo que ao $8^{0}$ dia as plantas \\
Fotoperíodo & recebam a luminosidade normal da estufa. \\
Concentração de $\mathrm{CO}_{2}$ & $12 \mathrm{~h}$ \\
\hline
\end{tabular}

Fonte: SHINOHARA (1994).

primeiras, neste trabalho, elas serão tratadas conjuntamente.

\section{a) Enxertia por fenda e por perfuração apical}

Estes métodos de enxertia são adequados às cucurbitáceas e, diferentemente do método de enxertia por aproximação, a plântula da cultivar deve encontrar-se em um estádio de crescimento inferior (folhas cotiledonares meio abertas) ao do porta-enxerto (abertura da primeira folha verdadeira). A figura $1 \mathrm{~b}$ apresenta o esquema das semeaduras para produção de plântulas de cucurbitáceas a serem utilizadas na enxertia por fenda e por perfuração apical. Neste método, o tempo médio entre a semeadura da cultivar e o transplante é de 20 a 30 dias.

A operação de enxertia apresenta uma pequena diferença quanto ao corte realizado no porta-enxerto, entre os métodos de fenda (Figura 3a) e o de perfuração apical (Figura 3b). Neste último, o hipocótilo do enxerto é perfurado diagonalmente, inserindo-se um estilete no seu ápice, o que dispensa o uso de pinça fixadora na pós-enxertia, ao invés de ser cortado lateralmente com uma lâmina, como no primeiro.

\section{b) Enxertia por estaca terminal}

Este é o método de enxertia mais adequado às solanáceas, podendo também ser empregado para cucurbitáceas. No momento da enxertia, tanto as plantas da cultivar como as do porta-enxerto devem encontrar-se no estádio de abertura da primeira folha verdadeira. Neste sentido, no caso das solanáceas, de maneira geral, cultivar e portaenxerto devem semear-se no mesmo dia. No caso das cucurbitáceas, consideram-se as diferenças de velocidade de crescimento das distintas espécies para planejar as semeaduras, as quais podem seguir o esquema apresentado na figura $1 \mathrm{a}$. A figura 4 representa os passos que configuram a operação de enxertia por estaca terminal de solanáceas.

\section{CONCLUSÕES}

A enxertia herbácea de hortaliças, sendo uma técnica exigente em mão-de-obra qualificada, é adequada a culturas e materiais genéticos de grande valor de mercado e para pequenas áreas de produção, como pode ser o cultivo em ambiente protegido de híbridos, sensíveis a determinadas condições edafo-climáticas adversas e cuja semente apresenta um alto custo. O cultivo intensivo de hortaliças em ambiente protegido tem ocasionado graves problemas de contaminação por patógenos de solo, cada vez mais difíceis de solucionar através de métodos tradicionais de controle, o que tem levado ao abandono de algumas áreas dedicadas à produção sob estufa. Neste sentido, a enxertia representa mais uma opção dentro das técnicas a serem adotadas em um manejo integrado da produção de hortaliças. Nos últimos anos, houve um incremento considerável da pesquisa sobre o assunto. Diferentes métodos de enxertia têm sido estudados e materiais genéticos importados de outros países vêm sendo testados como porta-enxertos, tanto por instituições de pesquisa, como por empresas produtoras de sementes do sudeste do Brasil. No que diz respeito aos materiais utilizados como porta-enxerto, devido à grande disponibilidade de recursos genéticos, encontrados nas diferentes regiões do país, pode-se evitar a dependência de materiais externos. Existe um campo vasto a ser explorado na pesquisa de materiais nacionais, que, por um lado, atendam às diferentes resistências que se buscam e, por outro, não depreciem a qualidade do produto colhido.

Ciência Rural, v. 33, n. 6, nov-dez, 2003. 


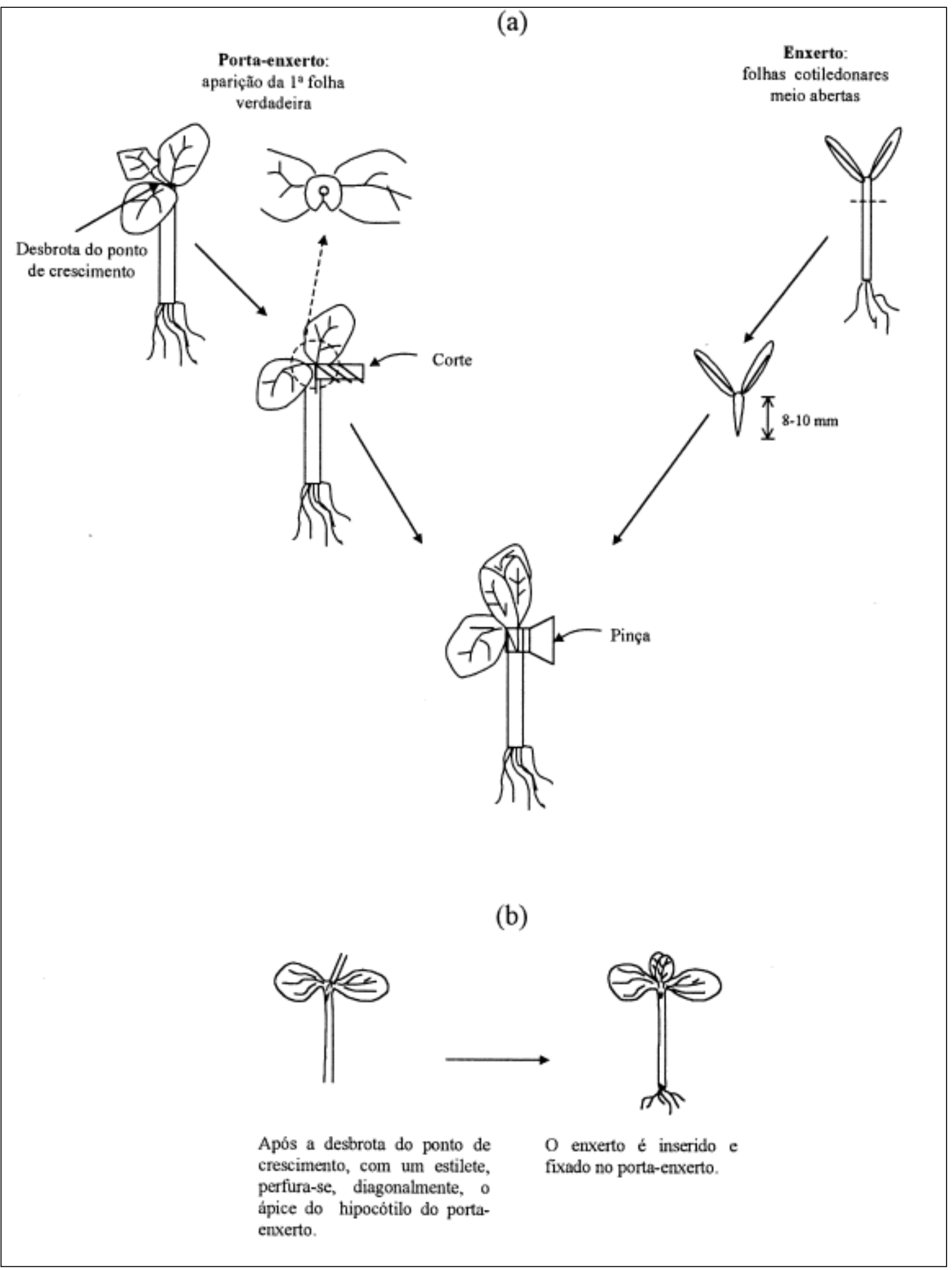

Figura 3 - Representação esquemática da operação de enxertia por fenda (a) e por perfuração apical (b) de cucurbitáceas.

Ciência Rural, v. 33, n. 6, nov-dez, 2003. 


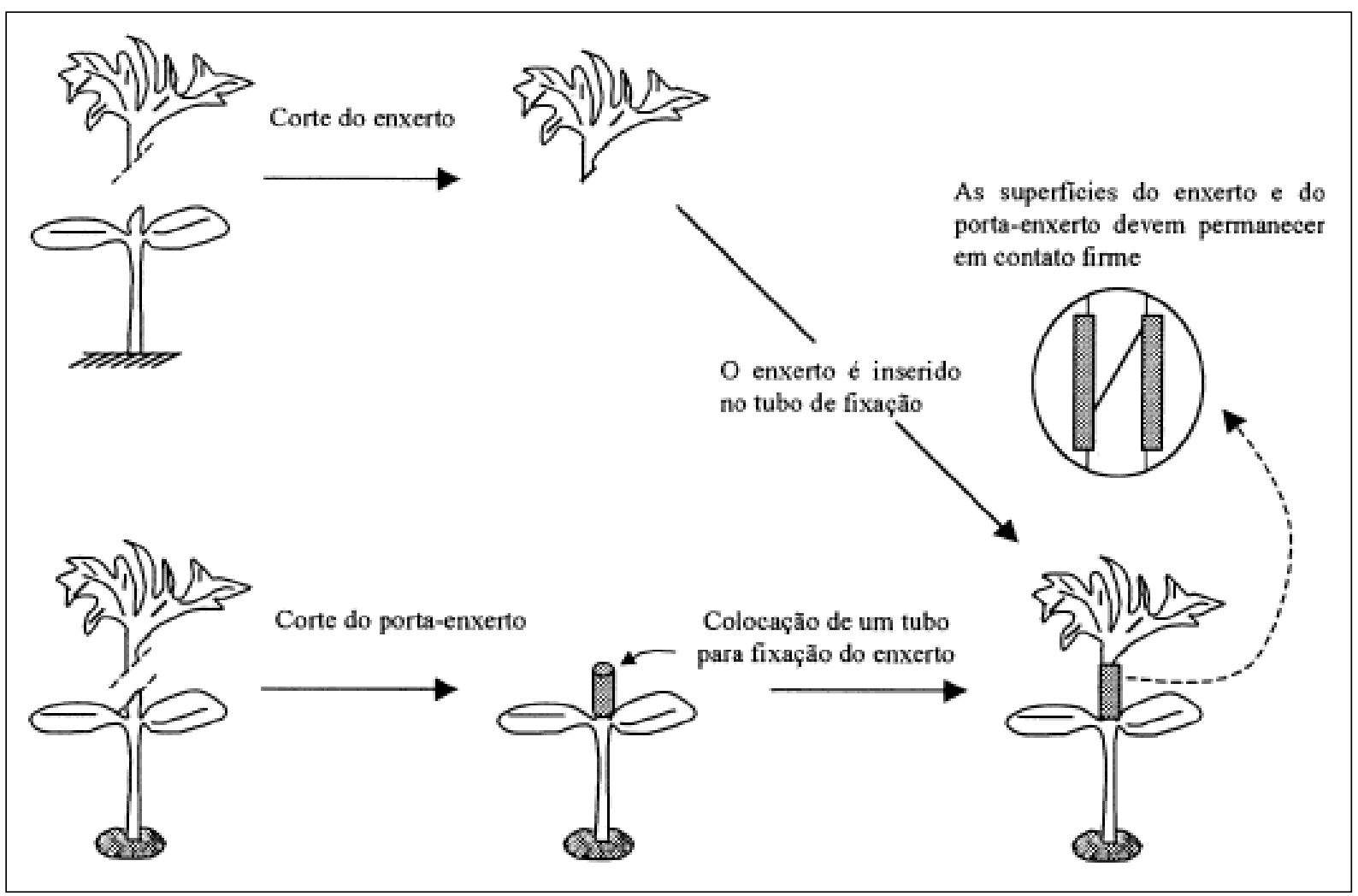

Figura 4 - Representação esquemática da operação de enxertia por estaca terminal de solanáceas.

\section{REFERÊNCIAS BIBLIOGRÁFICAS}

CANIZARES, K.A.L.; GOTO, R. Evaluación de tres métodos de injerto en pepino tipo japonés. In: CONGRESO PANAMEÑO, 1, Y CONGRESO IBEROAMERICANO DE APLICACIÓN DE LOS MATERIALES PLÁSTICOS EN LA AGricultura, 1., 1999, Ciudad de Panamá. Anales... Madrid : CEPLA (Comité Español de Plásticos en la Agricultura), 1999. p.140-145.

GONZÁLEZ, J. El injerto en hortalizas. In: VILARNAU, A.; GONZÁLEZ, J. Planteles: semilleros, viveros. Reus : Ediciones de Horticultura, 1999. Cap.9, p.121-128.

HARTMANN, H.T.; KESTER, D.E. Propagación de plantas. Ciudad de Méjico : Continental, 1967. 112p.

NAWASHIRO, T. Grafting of watermelon. Tsukuba : Tsukuba International Agricultural Training Centre (JICA), 1994. 12p. (Apostila, Vegetable Crops Production Course).
PEIL, R.M.N.; GÁLVEZ, J.L. Cultivo del tomate con la técnica de la lámina de nutrientes (NFT) en el sudeste español. In: CONGRESO PANAMEÑO, 1., Y CONGRESO IBEROAMERICANO DE APLICACIÓN DE LOS MATERIALES PLÁSTICOS EN LA AGRICULTURA, 1., 1999, Ciudad de Panamá. Anales... Madrid : CEPLA (Comité Español de Plásticos en la Agricultura), 1999. p.124-139.

PEIL, R.M.N.; GÁLVEZ, J.L.; MARTIN, A. Cultivo de pepino con técnica de solución nutritiva recirculante. In: CONGRESO IBÉRICO SOBRE GESTIÓN Y PLANIFICACIÓN DE AGUAS (SIMPOSIUM: EL AGUA Y SUS USOS AGRARIOS), 1., 1998, Zaragoza. Actas... Zaragoza : Universidad de Zaragoza, 1998. CD Rom, n. 208, 9p.

SHINOHARA, Y. Raising vegetable seedlings. Tsukuba : Faculty of Horticultural, 1994. 6p. (Apostila, Vegetable Crops Production Course).

TAKII SEED. New and standard varieties. Kyoto : Takii, s.d. 112p. (Vegetable catalog, 9). 